\title{
A comparison of the effect of dexamethasone and pethidine for prevention of shivering after spinal anesthesia in caesarean section: randomization clinical trial
}

\author{
Hamideh Gholami ${ }^{1}$, Yousef Moradi ${ }^{2}$, Zaher Khazaei ${ }^{3 \oplus}$, Shahrzad Tehrani $^{4}$,*
}

${ }^{1}$ Assistant Professor of Obstetrics and Gynecology, Zanjan University of Medical Sciences, Zanjan, Iran

${ }^{2}$ Pars Advanced and Minimally Invasive Medical Manners Research Center, Pars Hospital, Iran University of Medical Sciences, Tehran, Iran

${ }^{3}$ Student Research Committee, Sabzevar University of Medical Sciences, Sabzevar, Iran

${ }^{4}$ Department of Gynecology and Obstetrics, Zanjan University of Medical Sciences, Zanjan, Iran

\section{Correspondence}

Shahrzad Tehrani, Department of Gynecology and Obstetrics, Zanjan University of Medical Sciences, Zanjan, Iran

Email: tehrani2243@gmail.com History

- Received: 19 April 2018

- Accepted: 14 August 2018

- Published: 21 September 2018

DOI : 10.15419/bmrat.v5i9.473

\section{Check for updates}

\section{Copyright}

(c) Biomedpress. This is an openaccess article distributed under the terms of the Creative Commons Attribution 4.0 International license.

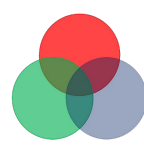

The Open Access Publisher

\begin{abstract}
Background: Postanesthetic shivering is one of the most common complications and problems after operations. Medications and drugs can be used to prevent postanesthetic shivering. The aim of this study is to compare the effects of Dexamethasone and Pethidine in preventing postanesthetic shivering after spinal anesthesia in Iranian women undergoing caesarean section. Method: This double-blind randomized clinical trial was performed in 66 pregnant women who were referred to Ayatollah Moosavi Hospital in Zanjan, Iran for elective cesarean section, from December 2011 to November 2012. All participants who have ASA I-II were randomly classified into three groups: Dexamethasone receivers (Group A), Pethidine receivers (Group B), and Normal Saline receivers (Group $\mathrm{C}$ ). Data were collected and analyzed using SPSS 16 software. IRCT registration number of this study is IRCT201112198469N1. Conclusion: Although statistically there was no significant difference between the three groups of Dexamethasone, Pethidine and Normal Saline receivers regarding shivering reduction; clinical complication rate in Dexamethasone group was lower comparedto Pethidine and Normal Saline groups. Results: There was no significant difference between three groups regarding shivering reduction. There were 11 (72.5\%) trembling cases in Normal Saline group, 6 cases (27.3\%) in Dexamethasone group, and 12 cases (54.5\%) in Pethidine group.

Key words: Dexamethasone, Pethidine, Postanaesth, Randomization Clinical Trial, Shivering, Spinal anesthesia
\end{abstract}

\section{INTRODUCTION}

Postanesthetic shivering is an unpleasant problem and one of the most common complications after operations, that occurs in 6.3 to 65 percent of patients in the recovery phase after surgeries ${ }^{1-3}$ and about $30 \%$ was epidural and spinal anesthesia ${ }^{4}$. Generally, all anesthesia dysregulate body temperature control $^{4-6}$. The incidence show to less patients are normal temperature ${ }^{6}$. Shivering is considered to be one of six important complications after general anesthesia $^{2}$. Many problems and side effects such as increasing postoperative pain, elevating tissue oxygen consumption, hypertension, tachycardia, increasing intracranial pressure (ICP), and other physiological changes ${ }^{2,4-9}$. Postanesthetic shivering is very unpleasant and complicated especially in patients with poor cardiac reserve ${ }^{10-12}$. Therefore, reducing postanesthetic shivering is very serious and important ${ }^{11}$. There are many pharmacological medications have been studied ${ }^{13}$. Medical methods and drugs can be used to prevent and reduce the postoperative shivering temperature threshold and the core and skin temperature gradient ${ }^{13}$. Opioids were mostly used and with more doses than in the past. Dexamethasone and Pethidine were two drugs that were used to reduce postoperative shivering and known to be effective $^{12}$. Between the two, Pethidine have been widely prescribed and is the first line in anesthesia ${ }^{14}$.

The aim of this study is to compare the effects of Dexamethasone and Pethidine in preventing shivering after spinal anesthesia in Iranian women undergoing caesarean section.

\section{METHODS}

\section{Ethical approval}

This study was approved by the Local Ethics Committee of Zanjan University of medical science, Zanjan, Iran and registered in the Iranian Registry of Clinical Trials (IRCT.ir); ID number: IRCT201112198469N1. In this study, informed consents were received from all individuals that participated in this study and their partners. 


\section{Experimental design}

This single blind randomized clinical trial study was performed in 66 pregnant women who experienced shivering following spinal anesthesia for elective cesarean section and were referred to obstetrics and gynecology department of Ayatollah Mousavi Hospital in Zanjan city affiliated Zanjan University of medical science, from December 2011 to November 2012. All participants who have ASA physical status (ASAPS) scale I-II and do not have any disorder or disease were enrolled in this study and randomly divided into three groups ( $n=22)$ (Figure 1). The drugs were intravenously injected to the patients. We randomly allocated our cases by Excel software using Rand between order. Allocation into each group was based on opening sealed and opaque envelopes indicating the drug name. Clinicians were not blinded to the treatment allocation.

Group 1: Dexamethasone, $0.6 \mathrm{mg} / \mathrm{kg}(10 \mathrm{~mL})$

Group 2: Pethidine, $0.5 \mathrm{mg} / \mathrm{kg}(10 \mathrm{~mL})$

Group 3: Normal Saline $(10 \mathrm{~mL})$

\section{Outcomes evaluation}

The temperature was measured and recorded for all patients at the entrance to the operating room. Prescription serum temperature was about 30 to $35^{\circ} \mathrm{C}$ and the operation temperature was about 23 to 25 ${ }^{\circ} \mathrm{C}$. The outcome variables are core temperature, nausea, headache, and shivering that were recorded before, and after surgery in the recovery room. Core temperature was measured by mercury thermometer. The frequency of nausea, headache, and shivering was measured through visual signs by physicians.

\section{Statistical analysis}

In this study, data were analyzed using SPSS software version 16. Descriptive analyses were performed including means and standard deviations (SD). Also, in this study, independent $\mathrm{T}$ test and One Way ANOVA were used to statistically test mean differences between groups and variables. Logistic Regression model was used to predict the adjusted odds ratio (OR). The level of significance was set at $\mathrm{p}<0.05$ for all analyses.

\section{RESULTS}

The results showed, mean and SD of age, BMI, body temperature, heart rate, systolic and diastolic blood pressure, and bleeding in all patients $(n=66)$ were $28.80 \pm 5.82,31.90 \pm 2.09,36.83 \pm 0.56,80.88 \pm$ $6.80,10.87 \pm 1.55,7.07 \pm 0.72$, and $930.76 \pm 111.385$ respectively (Table 1). At the same time, in Table 1, the mean and SD of age, BMI, and bleeding in groups treated with Dexamethasone, Pethidine, and normal saline were $28 \pm 6.27,31.70 \pm 1.90$, and $772.73 \pm$ $132.49,29.36 \pm 5.05,31.79 \pm 2.04$, and $740.00 \pm$ $117.14,29.41 \pm 6.24,32.22 \pm 2.37$, and $1279.55 \pm$ 1955.37, respectively. Those are not statistically different.

Table 2 introduced frequency of shivering, nausea and headache in the three groups. $16(72.7 \%)$ patients in the Dexamethasone group, $10(45.5 \%)$ patients in the Pethidine group, and 11 (50\%) patients in the Normal saline group had to shivering $(\mathrm{P}=0.149)$. Also, $45.5 \%$ patients in the Dexamethasone group, $40.9 \%$ patients in the Pethidine group, and 50\% patients in the Normal saline group experienced nausea, which is not statistically different $(\mathrm{P}=0.832)$ (Figure 2).

\section{DISCUSSION}

Previous studies showed some drugs can reduce the body core and skin temperature gradient and decrease the skin temperature ${ }^{3}$. On the other hand, Dexamethasone is effective in reducing shivering in patients by regulating immune responses ${ }^{12}$. Most studies showed that Dexamethasone is effective in preventing postoperative shivering with spinal anesthesia $^{15,16}$. The mechanism of post-anesthetic shivering can be established as a thermo-regulatory reaction to low body temperature that occurs during surgeries, which leads to clonic and tonic patterns ${ }^{3,4,16}$.

Our results showed that there was no significant difference between the three groups receiving Pethidine, Dexamethasone, and normal saline in headache complication. However, Dexamethasone prophylaxis was reported to have positive effects on headache after spinal anesthesia for cesarean section ${ }^{17}$. In this study, we showed that there was no significant difference between the three groups in nausea complication. Pethidine was shown to be more effective in reducing postoperative shivering after the cesarean section ${ }^{18}$. In some of the studies showed the efficacy of Pethidine in reduce and prevention of shivering after surgeries ${ }^{10,17}$. In the some studies, Dexamethasone and Pethidine were also reported to be equally effective in reducing and preventing postoperative shivering after surgeries $^{17}$.

In our study, no significant differences between the three groups were observed in vital signs. However, diastolic pressure was slightly lower in patients receiving Pethidine. The anti-shivering action of pethidine was inhibited by high dose of naloxone, which blocks both $\mu$ and $\mathrm{k}$ receptors, but not by low dose of naloxone which block only $\mu$ receptors ${ }^{19}$. A disadvantage of Pethidine is that it can cause respiratory depression 




Figure 1: Consort diagram of the trial.

Table 1: Comparison of the mean and SD variables in three groups

\begin{tabular}{|c|c|c|c|c|c|}
\hline Variable & Total $(n=66)$ & $\begin{array}{c}\text { Dexamethasone } \\
\qquad(\mathrm{n}=22)\end{array}$ & $\begin{array}{c}\text { Pethidine } \\
(\mathrm{n}=22)\end{array}$ & $\begin{array}{c}\text { Normal Saline } \\
\quad(n=22)\end{array}$ & P-value \\
\hline Age (year) & $28.80 \pm 5.82$ & $28 \pm 6.27$ & $29.36 \pm 5.05$ & $29.41 \pm 6.24$ & 0.125 \\
\hline BMI $(\mathrm{kg} / \mathrm{m} 2)$ & $31.90 \pm 2.09$ & $31.70 \pm 1.90$ & $31.79 \pm 2.04$ & $32.22 \pm 2.37$ & 0.683 \\
\hline $\begin{array}{l}\text { Body tempera- } \\
\text { ture }\left({ }^{0} \mathrm{C}\right)\end{array}$ & $36.83 \pm 0.56$ & $36.88 \pm 0.59$ & $36.83 \pm 0.55$ & $36.78 \pm 0.56$ & 0.374 \\
\hline $\begin{array}{l}\text { Heart rate } \\
(\mathbf{n} / \mathbf{m i n})\end{array}$ & $80.88 \pm 6.80$ & $78.50 \pm 5.50$ & $81.45 \pm 8.39$ & $82.68 \pm 5.74$ & 0.211 \\
\hline $\begin{array}{l}\text { Systolic Blood } \\
\text { pressure } \\
(\mathrm{mmHg})\end{array}$ & $10.87 \pm 1.55$ & $10.72 \pm 2.20$ & $10.93 \pm 1.17$ & $10.97 \pm 1.09$ & 0.855 \\
\hline $\begin{array}{l}\text { Diastolic } \\
\text { Blood pressure } \\
(\mathrm{mmHg})\end{array}$ & $7.07 \pm 0.72$ & $7.20 \pm 0.72$ & $6.78 \pm 0.835$ & $7.25 \pm 0.49$ & 0.068 \\
\hline Bleeding & $\begin{array}{c}930.76 \pm \\
111.385\end{array}$ & $\begin{array}{c}772.73 \pm \\
132.49\end{array}$ & $\begin{array}{c}740.00 \pm \\
117.14\end{array}$ & $\begin{array}{c}1279.55 \pm \\
1955.37\end{array}$ & 0.217 \\
\hline
\end{tabular}

in the presence of previously administered opioids or anesthetics. Moreover, nausea and vomiting are also important side effects of Pethidine ${ }^{20}$.

The limitation of this study is small sample size. Hence, further studies with a larger sample size is recommended.

\section{CONCLUSION}

Although statistically there was no significant difference between the three groups of Dexamethasone, Pethidine and Normal Saline receivers regarding the reduction of shivering ${ }^{13-16}$; because Pethidine is an opioid analgesic, it may interact with another drugs and lead to respiratory depression ${ }^{16}$, and clinical complication rate in Dexamethasone group was lower comparing to Pethidine and Normal Saline groups. Hence, Dexamethasone prophylaxis is recommended.

\section{COMPETING INTERESTS}

The authors declare no conflict of interest.

\section{AUTHORS' CONTRIBUTIONS}

All authors contributed to the design of the research. $\mathrm{HGH}, \mathrm{YM}$, and ST collected the data. ZKH, YM con- 


\begin{tabular}{|c|c|c|c|c|c|}
\hline Variable & Total $(n=66)$ & Dexamethasone $(n=22)$ & Pethidine $(n=22)$ & Normal saline $(\mathrm{n}=\mathbf{2 2})$ & $P$-value \\
\hline \multicolumn{6}{|c|}{ Shivering } \\
\hline Yes & $37(56.1 \%)$ & $16(72.7 \%)$ & $10(45.5 \%)$ & $11(50 \%)$ & \multirow{2}{*}{0.149} \\
\hline No & $29(43.9 \%)$ & $6(27.3 \%)$ & $12(54.5 \%)$ & $11(50 \%)$ & \\
\hline \multicolumn{6}{|l|}{ Nausea } \\
\hline Yes & $30(45.5 \%)$ & $10(45.5 \%)$ & $9(40.9 \%)$ & $11(50 \%)$ & \multirow{2}{*}{0.832} \\
\hline No & $36(54.5 \%)$ & $12(54.5 \%)$ & $13(59.1 \%)$ & $11(50 \%)$ & \\
\hline \multicolumn{6}{|c|}{ Headache } \\
\hline Yes & $20(30.3 \%)$ & $6(27.3 \%)$ & $5(22.7 \%)$ & $9(40.9 \%)$ & \multirow[t]{2}{*}{0.394} \\
\hline No & 46 (69.7\%) & $16(72.7 \%)$ & $17(77.3 \%)$ & 19 (59.1\%) & \\
\hline
\end{tabular}

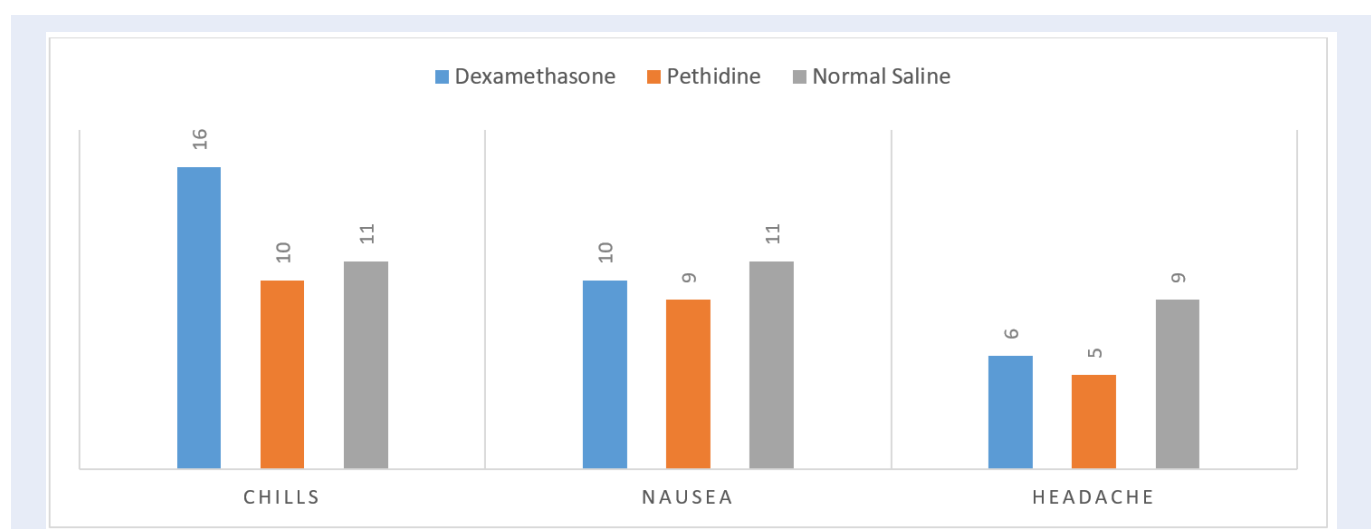

Figure 2: Comparison of the frequency the incidence of outcomes in three groups.

ducted analysis and interpretation of data. All authors drafted the first version. HGH, ZKH, YM, and ST edited the first draft. All authors reviewed, commented and approved the final draft.

\section{FINANCIAL SUPPORT}

Zanjan University of medical science, Zanjan, Iran.

\section{ABBREVIATIONS}

RCT: Randomized, Controlled Trial

\section{REFERENCES}

1. Khorasanizadeh F, Hassanloo J, Khaksar N, Taheri SM, Marzaban M, Rashidi BH. Epidemiology of cervical cancer and human papilloma virus infection among Iranian women - analyses of national data and systematic review of the literature. Gynecologic Oncology. 2013;128:277-81. Available from: DOI:10.1016/j.ygyno.2012.11.032.

2. Farzi F, Sobhani A, Keshtkar A. Effect of Dexamethasone before induction of anesthesia on postoperative shivering. Journal Of Guilan University of Medical Sciences. 2002;10:42-49.

3. EntezariasI M, Isazadehfar K. Dexamethasone for prevention of postoperative shivering: a randomized double-blind comparison with pethidine. International Journal of Preventive
Medicine. 2013;4:818-24.

4. Kurz A. Physiology of thermoregulation. Best Practice \& Research Clinical Anaesthesiology. 2008;22:627-44. Available from: DOI:10.1016/j.bpa.2008.06.004.

5. Iqbal A, Ahmed A, Rudra A, Wankhede RG, Sengupta S, Das T. Prophylactic granisetron vs pethidine for the prevention of postoperative shivering: a randomized control trial. Indian Journal of Anaesthesia. 2009;53:330-4.

6. Hoseinkhan Z, Behzadi M. Morphine, Pethidine and Fentanyl in post-operative shivering control: a randomized clinical trial. Tehran Univ Med J. 2006;64:57-63.

7. MacArthur RA, Wang LC. Physiology of thermoregulation in the pika, Ochotona princeps. Canadian Journal of Zoology. 1973;51:11-6. Available from: DOI:10.1139/z73-002.

8. Broderick AJ. Small-dose dexamethasone improves quality of recovery scores after elective cardiac surgery. Journal of Cardiothoracic and Vascular Anesthesia. 2013;27:e3. Available from: DOI:10.1053/j.jvca.2012.09.014.

9. Murphy GS, Sherwani SS, Szokol JW, Avram MJ, Greenberg SB, Patel KM. Small-dose dexamethasone improves quality of recovery scores after elective cardiac surgery: a randomized, double-blind, placebo-controlled study. Journal of Cardiothoracic and Vascular Anesthesia. 2011;25:950-60. Available from: DOI:10.1053/j.jvca.2011.03.002.

10. AsI ME, Isazadefar K, Mohammadian A, Khoshbaten M. Ondansetron and meperidine prevent postoperative shivering after general anesthesia. Middle East Journal of Anaesthesiology. 2011;21:67-70. 
11. Roy JD, Girard M, Drolet P. Intrathecal meperidine decreases shivering during cesarean delivery under spinal anesthesia. Anesthesia and Analgesia. 2004;98:230-4. Available from: Doi:10.1213/01.ane.0000093251.42341.74.

12. Zavareh SM, Morovati L, Koushki AM. A comparative study on the prophylactic effects of ketamine, dexamethasone, and pethidine in preventing postoperative shivering. Journal of Research in Medical Sciences. 2012;000:17.

13. Gecaj-Gashi A, Hashimi M, Sada F, Salihu S, Terziqi H. Prophylactic ketamine reduces incidence of postanaesthetic shivering. Nigerian Journal of Medicine. 2010;19:267-70. Available from: DOI:10.4314/njm.v19i3.60181.

14. Dal D, Kose A, Honca M, Akinci SB, Basgul E, Aypar U. Efficacy of prophylactic ketamine in preventing postoperative shivering. British Journal of Anaesthesia. 2005;95:189-92. Available from: DOI:10.1093/bja/aei148.

15. Ekemen S, Yelken B, Ilhan H, Tokar B. A comparison of analgesic efficacy of tramadol and pethidine for management of postoperative pain in children: a randomized, controlled study. Pediatric Surgery International. 2008;24:695-8. Available from: DOI:10.1007/s00383-008-2147-3.
16. Hadi MA, Kamaruljan HS, Saedah A, Abdullah NM. A comparative study of intravenous patient-controlled analgesia morphine and tramadol in patients undergoing major operation. The Medical journal of Malaysia. 2006;61:570-576.

17. Kim YS, Kim Yl, Seo KH, Kang HR. Optimal dose of prophylactic dexmedetomidine for preventing postoperative shivering. International Journal of Medical Sciences. 2013;10:132732. Available from: DOI:10.7150/ijms.6531.

18. Pazoki S, Noroozi A, Shadman AH. Comparison effect of different doses of Ketamine with Pethedine in reducing postoperative shivering after cesarean section. Journal of Arak University of Medical Sciences. 2009;12:9-16.

19. Iqbal A, Ahmed A, Rudra A, Wankhede RG, Sengupta S, Das T. Prophylactic granisetron vs pethidine for the prevention of postoperative shivering: a randomized control trial. Indian Journal of Anaesthesia. 2009;53:330-4.

20. Wrench IJ, Cavill G, Ward JE, Crossley AW. Comparison between alfentanil, pethidine and placebo in the treatment of post-anaesthetic shivering. British Journal of Anaesthesia. 1997;79:541-2. Available from: DOI:10.1093/bja/79.4.541.

\section{Scan to download the article}

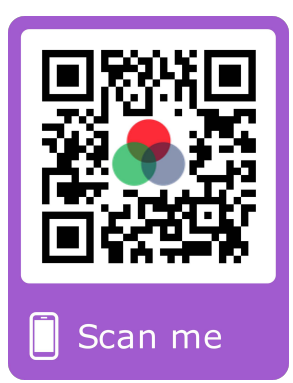

